\title{
CARDIOVASCULAR CHANGES IN WORKERS EXPOSED TO FINE PARTICULATE DUST
}

\section{ALICJA BORTKIEWICZ ${ }^{1}$, ELŻBIETA GADZICKA ${ }^{1}$, GRAŻYNA STROSZEJN-MROWCA², AGATA SZYJKOWSKA ${ }^{1}$, WIESŁAW SZYMCZAK ${ }^{3}$, WIESŁAWA KOSZADA-WŁODARCZYK ${ }^{1}$, and IRENA SZADKOWSKA-STAŃCZYK²}

\author{
${ }^{1}$ Nofer Institute of Occupational Medicine, Łódź, Poland \\ Department of Work Physiology and Ergonomics \\ ${ }^{2}$ Nofer Institute of Occupational Medicine, Łódź, Poland \\ Department of Environmental Health Hazards \\ ${ }^{3}$ University of Lodz, Łódź, Poland \\ Institute of Psychology
}

\begin{abstract}
Objectives: Epidemiological studies provide evidence that airborne particulate matter may contribute to the increased incidence and mortality rates due to pulmonary and cardiovascular diseases. Only some of them address the problem of occupational exposure to particulate air pollution. The aim of our study was to assess cardiovascular reaction and autonomic regulation in workers exposed to fine particles. Materials and Methods: All workers had medical examination, resting ECG with heart rate variability analysis (HRV), 24-h ECG, and ambulatory blood pressure monitoring (ABPM) performed. The subjects were 20 male workers (mean age: 32.14 .0 year) of a ceramic ware factory exposed to the dust and 20 workers who were not exposed (mean age: 39.4 \pm 7.8 year). The period of employment under exposure amounted to 5.6 \pm 2.1 year. Dust exposure was measured using individual dosimeters. Results: The geometric mean total dust concentration was $44 \pm 1.5 \mathrm{mg} / \mathrm{m}^{3}$ and the FPD (fine particulate dust) concentration amounted to $11.5 \pm 1.6 \mathrm{mg} / \mathrm{m}^{3}$. No abnormalities were noted in the resting ECG in both groups, in 24-h ECG 2 subjects, both from exposed and control groups, had ventricular heart rhythm and repolarization disturbances. Blood pressure in ABPM, both systolic as well as diastolic, was normal and did not differ between the groups. Resting heart rate in the exposed group was significantly lower $(p=0.038)$ than in the control group. In the exposed group STD R-R from short-term records was significantly higher $(\mathrm{p}=0.01)$. Fast Fourier Transform $(\mathrm{FFT})$ analysis showed that the low frequency power spectrum (LF) did not differ in the exposed and the control group, while high frequency (HF) was significantly higher in the exposed group. LF/HF ratio was significantly lower in the exposed in comparison with the control group. Conclusions: Although we did not reveal significant abnormalities in ECG as well as in ABPM in the exposed group, it seems that neurovegetative disturbances (parasympathetic predominance) may serve as an early indicator of fine particulate dust effect on cardiovascular system.
\end{abstract}

Key words:

Ceramic industry, Heart rate variability, Air pollution, Respirable dust, Blood pressure monitoring, ABPM

\footnotetext{
This study was supported by Nofer Institute of Occupational Medicine: IMP 4.10./2004 "Occupational exposure to ultrafine particles (PM < $10 \mu \mathrm{m})$ " as a risk factor for cardiovascular diseases (manager of project: Irena Szadkowska-Stańczyk, prof.) and IMP 20.5 "Return to work after first acute coronary syndrome: The analysis of factors that affect the continuation of occupational activity" (manager of project: Elżbieta Gadzicka, MD, PhD).

Received: May 14, 2013. Accepted: December 18, 2013.

Corresponding author: A. Bortkiewicz, Nofer Institute of Occupational Medicine, Department of Work Physiology and Ergonomics, św. Teresy 8, 91-348 Łódź, Poland (e-mail: alab@imp.lodz.pl).
} 


\section{INTRODUCTION}

Seaton et al. in their report, published in 1995, put forward a hypothesis that inhalation of fine particles, which are a major communal air pollutant, may lead to the development of inflammatory reaction in lungs [1]. This is associated with a release of specific mediators that modify blood coagulation properties and thus, lead to ischaemic effects. Two years later Sjoegren (1997) extended this hypothesis to occupational exposure to fine particles. The literature review, published by Sjoegren et al. in 1997, includes findings that indicate the increased risk of ischaemic heart disease (IHD) among workers exposed to dust containing a specific agent e.g. quartz, asbestos, PAHs, arsenic, beryllium, lead, organic dust, wood dust, paper dust and welding fumes [2]. Also, a number of studies have linked the increased risk of IHD with work under high-level exposure to non-specified dust [3-5].

Epidemiologic studies provide evidence that airborne particulate matter may contribute to the increased incidence and mortality rates due to pulmonary and cardiovascular diseases [6,7]. In addition, Pope et al. and Peters et al. observed elevated heart rate in the exposed people $[8,9]$. Current epidemiologic studies show that the elevated heart rate is by itself a factor of the increased risk of arterial hypertension, IHD and a sudden cardiac death [10-13]. Heart rate directly determines myocardial oxygen demand and therefore, even with no sclerotic changes, elevated heart rate may result in heart muscle ischaemia.

Recently, a number of reports have been published on the possible relationship between fine particle exposure and impaired neurovegetative regulation of the cardiovascular function. This regulation may be assessed using the heart rate variability (HRV) analysis. The time- and frequencydomain HRV parameters make it possible to evaluate the sympathetic and parasympathetic activity. As revealed in the studies by Liao, Pope, Gold and Magari, people who are exposed show a decreased total heart rate variability and parasympathetic activity and an increased sympathetic activity $[8,14-16]$. The dominance of the sympathetic function and the resulting decreased protection of the heart by the parasympathetic activity predisposes not only to arterial hypertension but also to the heart rhythm disturbances and the development of IHD [17,18]. HRV decrease could be connected with a number of negative consequences. Prospective studies have revealed that the patients with heart rhythm disturbances in 24-h ECG and a decreased HRV are twice as much at risk of a sudden death as the patients who have similar ventricular arrhythmias but a normal HRV [19].

The aim of our study was to assess cardiovascular reaction and autonomic regulation in workers exposed to fine particulate dust.

\section{MATERIAL AND METHODS}

\section{Selection of the study population}

The study population comprised employees of a ceramic ware factory exposed to dust with a relatively high fine particulate fraction in the molding, glazing and sorting departments [20]. The study was conducted in a group of male workers occupationally exposed to dust containing high proportions of fine (below $10 \mu \mathrm{m}$ ) particles, at concentrations above the current hygienic standards, and in a control group consisting of occupationally non-exposed male workers (dust was not listed as a harmful agent in the workplaces of the control group). To eliminate the effect of possible confounders, the exposed and control groups were similar with respect to the distribution of demographic and social characteristics, such as: lifestyle, dietary habits, living environment, and work-related energy expenditure.

\section{Exposed group}

The exposed group comprised male workers employed in 2 departments of the plant with high dust emission. The plant was operated on a 2-shift basis i.e. 6 a.m. - 2 p.m. - 
morning shift, 2-10 p.m. - afternoon shift. The study subjects were 20 male workers, $32.1 \pm 4.0$ years of age (range: 26-41 years), who have been occupationally exposed to dust for 1 up to 7 years.

\section{Control group}

The control group consisted of male workers employed in the same plant, in packing- and storage departments. None of the jobs performed by the controls was associated with exposure to dust at concentrations higher than those normally found in office rooms. The system and nature of the job, as well as energy expenditure were the same in both groups. In total, the control group comprised 20 male workers at the age ranging from 35 to 52 years. Characteristics of the groups is presented in Table 1.

The tests were scheduled in such a way so as to ensure that exposure-free time was $48 \mathrm{~h}$ in the case of all the subjects.

The period of $48 \mathrm{~h}$ was considered sufficient for elimination of the fine particulate dust, which was inhaled during 8-h occupational exposure, from the circulating blood [21]. Thus, in the workers who finished work on Friday, after the morning shift, examinations started on Monday, before the afternoon shift. In the workers who finished work on Saturday, after the morning shift, examinations started on Tuesday, before the afternoon shift. The same timetable was used for the control group to ensure identical working conditions (afternoon shift), resting conditions ( 2 days off-duty before the test) and sleep.

\section{Assessment of exposure}

Measurements of concentrations of the inhalable and respirable dust in the selected workplaces were performed simultaneously with other determinations during the first day of work. Air samples were collected using personal samplers provided with 7-hole tip for inhalable, and with a cyclones for respirable dust. The samples were collected during $3 / 4$ of the work shift according to the relevant Polish Standard, PN-Z-04008-7:2002P [22]. Determinations of the inhalable and respirable dust were performed according to the Polish Standards PN-Z-04030-5:1991 [23] and PN-Z-04030-6:1991P [24].

Particle size distributions in the inhalable dust were determined with the GRIMM 1105 laser dust monitor adjusted so as to meet the requirements of the conventions quoted in PN-EN 481:1998P [25]. The monitor recorded concentrations (in $\mu \mathrm{g} / \mathrm{m}^{3}$ ) of the inhalable dust, the thoracic and the respirable fractions, and the concentrations of dust particles with diameters above $0.5 \mu \mathrm{m} ; 1 \mu \mathrm{m}$;

Table 1. Characteristics of the study population (one way analysis of variance)

\begin{tabular}{|c|c|c|c|}
\hline \multirow[b]{2}{*}{ Variable } & \multicolumn{2}{|c|}{ Studied group } & \multirow[b]{2}{*}{$\mathrm{p}$} \\
\hline & $\begin{array}{c}\text { exposed } \\
(\mathrm{N}=20)\end{array}$ & $\begin{array}{c}\text { control } \\
(\mathrm{N}=20)\end{array}$ & \\
\hline Age (years) & $32.1 \pm 4.0$ & $39.4 \pm 7.8$ & 0.05 \\
\hline Employment period (years) & $5.6 \pm 2.1$ & $5.2 \pm 2.0$ & ns \\
\hline Energy expenditure (kcal / work shift) & $1623.0 \pm 9.8$ & $1615.0 \pm 1.1$ & ns \\
\hline Diagnosed diseases: hypertension (n) & 1 & 2 & \\
\hline Subjective cardiovascular symptoms, $\mathrm{n}(\%)$ & $5(25)$ & $5(25)$ & ns \\
\hline BMI & $24.0 \pm 2.9$ & $26.6 \pm 2.9$ & ns \\
\hline Smokers (> 10 cigarettes/day), $\mathrm{n}(\%)$ & $12(60)$ & $12(60)$ & ns \\
\hline
\end{tabular}

BMI - body mass index $=$ body mass $/$ height ${ }^{2}\left(\mathrm{~kg} / \mathrm{m}^{2}\right)$.

ns - non-significant. 
$2 \mu \mathrm{m} ; 3.5 \mu \mathrm{m} ; 5 \mu \mathrm{m} ; 7.5 \mu \mathrm{m} ; 10 \mu \mathrm{m} ; 15 \mu \mathrm{m}$ at one-minute intervals. The monitor was placed as close as possible to the worker breathing zone. The worker breathing zone, according to the definition from European norm PNEN 1540:2004P [26], is "the space around the worker's face from where he takes the breath". In stationary sampling the aspirator was located on the level of $1 \mathrm{~m} 50 \mathrm{~cm}$ from the floor in the central point of workers' operations. At selected locations, the analyses were performed during one 8-h work shift.

The mineral compounds and the content of free crystalline silica (FCS) in the samples of inhalable and respirable dust were analysed by the use of the Infra-Red (IR) Spectrometry. Results of FCS determinations were expressed in terms of percentage of mass. Detection limit was on the level of $0.2 \%$. Protective masks were not used systematically, because in the workers' opinion they disturbed their ventilation.

\section{Medical and electrocardiological examination}

Not only did the methods used in this study make it possible to detect existing pathological changes, but also some early symptoms of autonomic nervous dysfunction that may lead to the development of cardiovascular diseases in the future.

\section{Assessment of health condition}

The workers underwent a general medical examination with office blood pressure measurement, and an interview oriented towards the risk factors of cardiovascular diseases, such as: family history of metabolic and cardiovascular diseases and complaints, education, professional career, dietary habits, physical activity and intake of condiments.

\section{Resting ECG}

A routine 12-lead ECG was recorded using a MEDEA system (Gliwice, Poland). The results were evaluated using generally adopted standards.

\section{4-h Holter ECG}

The subjects had their Holter ECG recorded by a Medilog Suprima 12 (Oxford, England) unit from 3 bipolar leads corresponding to precardiac V1, V3, and V5 leads in conventional ECG. The sampling time was $1024 \mathrm{~Hz}$. The results were classified as pathological according to the standards proposed by the Polish Cardiac Society [27].

The results of the Holter 24-h monitoring were also used to assess the 24-h heart rate, assuming values up to 87 beats/min to be normal.

The Holter 24-h monitoring was performed during normal daily occupational and non-occupational activities of the workers.

\section{HRV analysis based on the short-term ECG records}

HRV was assessed by analysing 512 consecutive normal heart cycles recorded by the use of ECG, using a MedeaHRV (Gliwice, Poland) unit. ECG records were made from 3 orthogonal Frank leads with the patient in a horizontal position, after 10-min. rest, during spontaneous breathing. The sampling time was $500 \mathrm{~Hz}$. Considering that HRV parameters were considerably affected by the time of the day, intake of food, drugs or condiments, etc. The examinations were performed in standard conditions. The workers were examined immediately before work, $2 \mathrm{~h}$ after a light meal. Before the examination, the patients refrained from the intake of drinks containing caffeine or alcohol and from smoking tobacco. None of the examined subjects took drugs which might affect autonomic nervous system (such as e.g. beta blockers).

Short-term ECG records were used to calculate timedomain and frequency-domain HRV indices. Statistical analysis made it possible to calculate the following timedomain parameters: mean R-R interval (AVG R-R); R-R standard deviation (STD R-R); median (MED), modal (MOD), minimum (MIN) and maximum (MAX) R-R intervals. R-R interval was also the subject to the Fast Fourier Transformation (FFT) using Blackman-Harris window. 
The power spectrum density (area covered by the power spectrum) was computed for the following frequency bands:

- very low (VLF): 0.0167-0.05 Hz;

- low (LF): 0.05-0.15 Hz;

- high (HF): 0.15-0.35 Hz;

- ultra high (UHF): 0.35-0.50 Hz;

- expressed as a percentage of spectrum power in the $0.0-2.5 \mathrm{~Hz}$ range.

According to the commonly adopted interpretation, the HF power spectrum is parasympathetic-mediated, while the LF one is sympathetic-mediated. The LF/HF ratio indicates a sympatho-vagal balance [28].

\section{Blood pressure monitoring (ABPM)}

24-h ABPM was performed by the use of an Acutracker DX (Oxford) unit during normal professional and other activities. The measurements were performed automatically every $0.5 \mathrm{~h}$. Thus, 48 measurements were obtained during each 24 -h period. The mean heart rate and systolic and diastolic blood pressure during the whole 24-h period (HRO, BPSO, BPDO), during daily activity (HRD, BPSD, BPDD) and at night (HRN, BPSN, BPDN) were determined.

Values recommended by Staessen, calculated by metaanalysis from 24-h records of blood pressure in a large population of healthy people $(\mathrm{N}=2638)$ of various age were used as reference [29]. These values were used as the reference values due to the possibility to compare the results with other groups examined earlier by the authors of this paper.

Additionally, the day-night ratios were determined for heart rate as well as systolic and diastolic blood pressure (BPSD/BPSN, BPDD/BPDN). The subjects with BP ratio lower than 1.1 were called 'non-dippers' (subjects without a physiological nocturnal drop in systolic and/or diastolic blood pressure). ABP 24-h monitoring enables indication of groups with a low and high risk of hypertension [30-34]. The method is also effective when it comes to diagnosing hypertension, particularly resistant and in the unstable period of the disease, as it eliminates the "white coat hypertension" effect [31,35,36].

\section{Assessment of energy expenditure (workload)}

For each type of the work post, the overall level of workload was determined based on the estimates for energy expenditure (gasometry), static workload and work strain due to the monotype working movements according to the method of Kirschner and Kock. The energy expenditure was determined based on lung ventilation, which was measured by WE-4 Meter (Central Institute for Labour Protection-CILP, Poland). The measurements were continued for $10 \mathrm{~min}$ for each kind of individual operation during the subjects' normal activities in their workplaces. Based on these measurements, energy expenditure per work shift was calculated. Before the measurements, workplace characteristics were determined by observation and interviews with the workers and their managers.

\section{Ethics}

The subjects gave their written informed consent to take part in the study. The study protocol was approved by the regional Biomedical Ethics Committee.

\section{Statistics}

The following methods were used in the statistical analysis: one-way analysis of covariance with the age and alcohol intake variables as confounding variables, 2-factor analysis of variance with repeated measures on one factor [37], linear regression model [38] and logistic regression model [39].

\section{RESULTS}

\section{Assessment of exposure}

Table 2 shows results of the measurements of concentrations of the inhalable and respirable dust in the exposed and control groups and the particle size analysis. In the 
Table 2. Dust concentration and particle size analysis according to the mass levels in the subjects and controls' workplaces

\begin{tabular}{ccccccccc}
\hline \multirow{2}{*}{ Studied group } & Dust & $\begin{array}{c}8 \mathrm{~h} \text { TWA } \\
(\mathrm{min} .-\mathrm{max}) \\
\left(\mathrm{mg} / \mathrm{m}^{3}\right)\end{array}$ & $\begin{array}{c}\text { GM } \\
\left(\mathrm{mg} / \mathrm{m}^{3}\right)\end{array}$ & GSD & $\begin{array}{c}\text { MMAD } \\
(\mu \mathrm{m})\end{array}$ & GSD & \multicolumn{2}{c}{\begin{tabular}{c} 
Particles \\
\cline { 5 - 8 }
\end{tabular}} \\
\hline Exposed $(\mathrm{N}=20)$ & inhalable dust & $4.9-130.3$ & 28.5 & 3.5 & 6.8 & 2.4 & 76.0 & 24.0 \\
& respirable dust & $1.3-33.6$ & 7.4 & 3.5 & & & & \\
Control $(\mathrm{N}=20)$ & inhalable dust & $0.2-3.2$ & 1.9 & 1.6 & 8.0 & 2.0 & 58.9 & 41.1 \\
& respirable dust & $0.1-0.9$ & 0.4 & 2.0 & & & & \\
\hline
\end{tabular}

$8 \mathrm{~h}$ TWA - time weighted average.

min. - minimum; max. - maximum.

GM - geometric mean.

GSD - geometric standard deviation.

MMAD - mass median aerodynamic diameter.

exposed workers, concentrations of the inhalable dust ranged from $4.9 \mathrm{mg} / \mathrm{m}^{3}$ to $130.3 \mathrm{mg} / \mathrm{m}^{3}$, geometric mean (GM) concentration was $28.5 \mathrm{mg} / \mathrm{m}^{3}$, while the geometric standard deviation (GSD) was 3.5. Concentrations of the respirable dust ranged from $1.3 \mathrm{mg} / \mathrm{m}^{3}$ to $33.6 \mathrm{mg} / \mathrm{m}^{3}, \mathrm{GM}$ was $7.4 \mathrm{mg} / \mathrm{m}^{3}$, and the GSD was 3.5 .

In the controls concentration of the inhalable dust ranged from $0.2 \mathrm{mg} / \mathrm{m}^{3}$ to $3.2 \mathrm{mg} / \mathrm{m}^{3}$, GM was $1.9 \mathrm{mg} / \mathrm{m}^{3}$, and the GSD was 1.6. Concentrations of the respirable dust ranged between $0.1 \mathrm{mg} / \mathrm{m}^{3}$ and $0.9 \mathrm{mg} / \mathrm{m}^{3}$, GM was $0.4 \mathrm{mg} / \mathrm{m}^{3}$, and GSD was 2.0.

As it is presented in Table 2 the inhalable dust collected in the workplaces of the exposed workers was characterised by a relatively high content of fine particles. The proportions (by mass) of particles with diameters below $10 \mu \mathrm{m}$ were: $76.0 \%$ in the exposed group and $58.9 \%$ in the control. Median values for the aerodynamic diameters of the inhalable dust were $6.8 \mu \mathrm{m}$ and $8.0 \mu \mathrm{m}$ for standard geometric deviation of 2.4 and 2.0, respectively.

Free crystalline silica was found in the dust from all the workplaces of the exposed group. Its content ranged from $18.2 \%$ to $23.1 \%$ in the case of inhalable dust and from $10.6 \%$ to $13.3 \%$ in the case of the respirable fraction.
Other mineral components included mostly kaolinite, gypsum, calcite and microcline.

\section{RESULTS OF MEDICAL AND ELECTROCARDIOLOGICAL EXAMINATIONS}

\section{Assessment of health condition}

In the group of the exposed workers, 5 people $(25 \%)$ reported cardiovascular symptoms such as breathlessness, pain, feeling of discomfort in the chest or cardiac arrhythmia. One person reported arterial hypertension in the anamnesis. However, during medical examination, 8 people had an elevated arterial blood pressure.

In the control group, the number of people reporting subjective cardiovascular symptoms was the same as in the study group (25\%). Two people reported arterial hypertension, while one reported congenital mitral insufficiency. During medical examination, blood pressure above $140 / 90 \mathrm{~mm} \mathrm{Hg}$ was detected in 8 people (including the person reporting hypertension in the anamnesis) which, according to WHO guidelines [40], is recognized as an arterial hypertension.

The percentage of people reporting subjective cardiovascular symptoms was the same in both groups: the study $(25 \%)$ and the control group (25\%). 
The exposed group included 6 overweight people (Body Mass Index - BMI > 25). BMI for the whole group was $24.0 \pm 2.9$, which was within the range of normal values.

The control group included 14 overweight people (BMI > 25). BMI for the whole group was 26.6 \pm 2.9 , which was higher than normal.

The number of current smokers in the exposed and control groups was the same, 12 subjects in each group. In the exposed group 11 people, and in the control group 9 people smoked 10-20 cigarettes daily. In the exposed group only 3 people reported alcohol drinking at least once per month, while the rest reported only occasional drinking. In the control group, as many as 18 people reported alcohol drinking at least once per month. However, nobody was a heavy drinker, because the one-time dose was only $50-150 \mathrm{ml}$ of vodka.

Lifestyle of both, the exposed and the control people was, generally speaking, healthy, with regular intake of meals. The majority (14 and 16 people, respectively) had 3 meals daily, while the remaining people had 4 and 5 meals daily. Their diets, in the first place, included vegetables, fruit, low-fat meat and fat (both of animal and vegetable origin).

Intake of meals by the controls, like that by the exposed people, was regular: 16 people had 3 meals daily, 2 people had 4, and 2 people had 2. Vegetables and fruit made up a large proportion of their diet. The study people preferred low-fat meat and consumed equal proportions of vegetable and animal fat.

The examined subjects, both from the exposed and control groups, practised some form of physical activity (walking, gardening, biking). Only 4 people from the exposed group, and 7 from the control group did not practise any form of physical exercise.

The comparison of lifestyle, dietary habits and physical activity shows that the study groups did not differ significantly, except for the aspect of alcohol drinking, which in the exposed group was significantly less frequent than in the controls (the percentage of non-drinkers was 69\% and $40 \%$, respectively). Effects of age and other confounders (BMI, alcohol) were eliminated using statistical methods.

\section{Resting ECG}

In the exposed group, abnormal ECG changes were noted in the case of 4 workers (20\%). Most of those changes were conduction disturbances, including incomplete Right Branch Bundle Block (RBBB incomp.) in 3 subjects and disturbed intraatrial conduction in one subject. In addition, left ventricular hyperthropy was observed in one subject. Ventricular hyperthropy is currently considered to represent an independent factor contributing to the development of arterial hypertension [41].

In the control group, abnormal ECG changes were also detected in 4 workers (20\%), including RBBB incomp. in 3 workers and atrioventricular block in one subject.

In the resting ECG neither ventricular nor supraventricular heart rhythm disturbances were noted in any group. Resting heart rate in the exposed group was $69.5 \pm 12.2$, and it was significantly lower $(\mathrm{p}=0.038)$ in comparison to that in the control group $(79.6 \pm 16.8)$.

\section{4-h Holter ECG monitoring}

In 24-h Holter ECG, it was found that the daily (24-h) heart rate did not differ between the exposed and control groups, and the values were $84 \pm 8$ and $84 \pm 9$, respectively. The number of people with 24-h heart rate above 87 beats/min was also the same, 9 in the exposed and 9 in the control group.

Both, in the exposed and the control groups, abnormalities in 24-h Holter records were found in the case of 2 workers. In the exposed workers we found repolarization abnormalities in a form of a significant lowering of the ST segment ( $>1 \mathrm{~mm}$ ) and wave T inversion in lead V5. In one subject from the control group we found ventricu- 
lar heart rhythm disturbances, which were not evident in the resting ECG and one subject showed conduction abnormalities in a form of RBBB incomp., also detectable in the resting ECG.

Only one worker from the subjects with the Holter-detected abnormalities reported cardiovascular symptoms in the anamnesis.

\section{HRV analysis}

Among the exposed workers, mean R-R interval (AVG $\mathrm{R}-\mathrm{R}$ ) in short-term ECG records was longer than in the controls, but the difference was not statistically significant. R-R standard deviation (STD R-R), that is a measure of HRV, was significantly lower $(\mathrm{p}<0.01)$ in the control $(33.2 \pm 14.6 \mathrm{~ms})$ than in the exposed group $(46.1 \pm 15.5 \mathrm{~ms})$. Values of time-domain HRV parameters are presented in Table 3.

Analysis by Fast Fourier Transform (FFT) showed that the total power spectrum and LF did not differ between the exposed and the control groups. VLF was significantly higher, while HF was significantly lower in the control in comparison with the exposed group. LF/HF ratio was significantly lower in the exposed group, suggesting a parasympathetic predominance in the exposed workers.
In the exposed group the $\mathrm{LF} / \mathrm{HF}$ ratio higher than 1 occurred only in 4 subjects $(20 \%)$, while in the control group - in 13 workers (65\%). Details of frequency domain parameters of HRV are shown in Table 3.

\section{4-h blood pressure monitoring (ABPM)}

By comparing results of ABPM in the control and exposed groups it has been found that the arterial blood pressure, both systolic and diastolic, within all the study periods (24-h, day, night) was normal and did not differ between the groups, just like indices of day/night systolic blood pressure ratio (Table 4).

Mean 24-h, daytime and nocturnal heart rate did not differ between the exposed and control groups. The day/night heart rate ratio did not differ between the groups either. The mean heart rate values in the examined groups and at different times of the recording are presented in Table 5.

The number of people with elevated ABP was found to be similar in the exposed and control groups, 3 and 5, respectively.

In the exposed group 3 people, and in the control group 6 people showed disturbances of $\mathrm{ABP}$ regulation manifested by the absence of normal physiological decrease of nocturnal systolic and diastolic arterial blood pressure.

Table 3. Time- and frequency-domain HRV parameters from short-term ECG adjusted means and SD (one way of covariance analysis)

\begin{tabular}{lccccccc}
\hline \multirow{2}{*}{ Studied group } & \multicolumn{6}{c}{ R-R $(\mathrm{ms})$} & \multicolumn{5}{c}{ Power in bands $(\%)$} \\
\cline { 2 - 8 } & STD & AVG & VLF & LF & HF & total & LF/HF \\
\hline Exposed $(\mathrm{N}=20), \mathrm{M} \pm \mathrm{SD}$ & $46.1 \pm 15.5$ & $846.9 \pm 133.7$ & $12.0 \pm 3.6$ & $25.4 \pm 4.6$ & $30.3 \pm 6.4$ & $75.0 \pm 5.5$ & $0.88 \pm 0.28$ \\
Control $(\mathrm{N}=20), \mathrm{M} \pm \mathrm{SD}$ & $33.2 \pm 14.6$ & $763.9 \pm 147.5$ & $15.3 \pm 3.6$ & $27.0 \pm 5.5$ & $24.1 \pm 8.6$ & $75.0 \pm 5.5$ & $1.26 \pm 0.48$ \\
$\mathrm{p}$ & 0.01 & 0.07 & 0.008 & ns & 0.013 & $\mathrm{~ns}$ & 0.0016 \\
\hline
\end{tabular}

$\mathrm{M}$ - mean; SD - standard deviation.

R-R - beat-to-beat; R-R STD - R-R standard deviation; R-R AVG - R-R average.

VLF - power spectrum within very low frequency range, below $0.05 \mathrm{~Hz}$.

LF - MWSA - Mayer wave, power spectrum within low frequency range $(0.05-0.15 \mathrm{~Hz})$.

$\mathrm{HF}$ - RSA - respiratory peak, power spectrum within high frequency range $(0.15-0.35 \mathrm{~Hz})$.

TPSc - total power spectrum within $0.0-0.5 \mathrm{~Hz}$ band.

$\mathrm{LF} / \mathrm{HF}$ - sympathovagal balance ratio.

ns - non-significant ( $\mathrm{p}>0.05)$. 


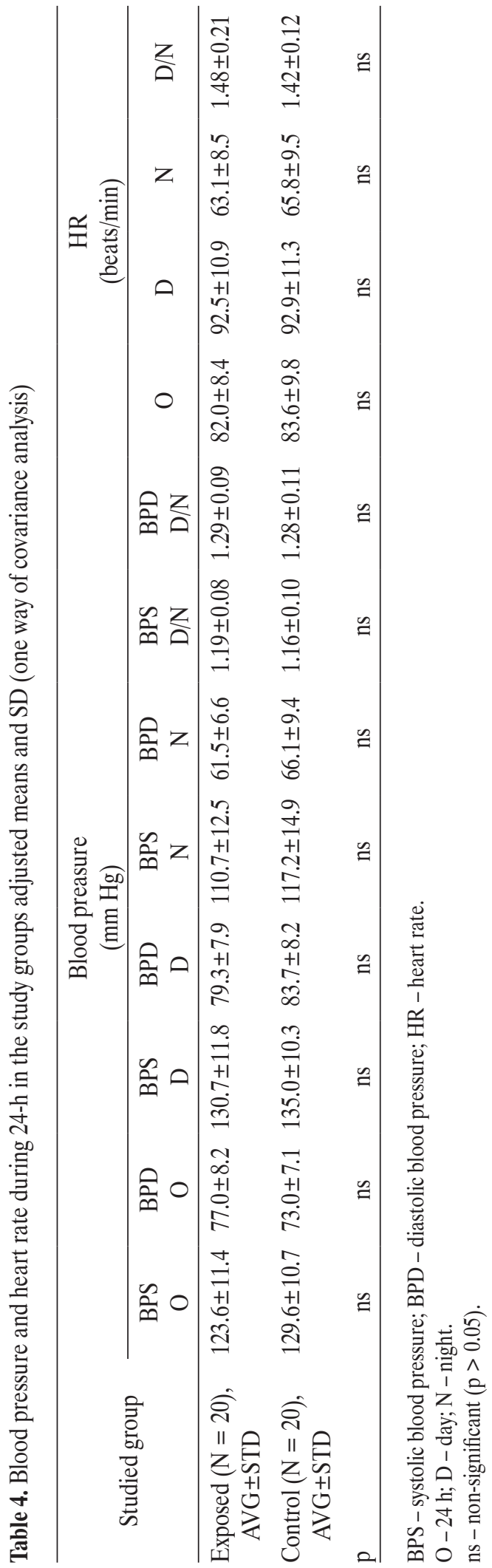

In the exposed group there were 9 workers with extreme nocturnal drop of the systolic blood pressure (so-called extreme-dippers), while in the control group there were only 5 extreme-dippers.

\section{Analysis of the relationship between HRV parameters and the level of exposure to the dusts}

The following 3 parameters characterising exposure were considered: duration of employment under exposure, concentration of total dust (PC) and concentration of the respirable fraction (PR). No significant correlation was found to occur between the HRV parameters and the level of exposure to the total dust or its respirable fraction.

\section{DISCUSSION}

Our results indicate that exposure to fine particulate dust significantly changes neurovegetative regulation of the circulatory function. The results of medical examinations, Holter 24-h ECG monitoring and ABPM did not show significant differences between the exposed and control groups.

Both, in the control and in the exposed groups, we found a lower number of people with abnormal ECG or arterial hypertension compared to the studied earlier groups exposed to electromagnetic fields of different frequencies or carbon disulfide [42-44]. One of the possible explanation of such a situation could be the young age of the subjects (mean age: 32 years) and a short duration of their employment under exposure (5 years mean). The time was too short to allow the development of pathologic changes in the cardiovascular system (such as disturbed heart rhythm, ischaemic changes or arterial hypertension).

The analysis of HRV parameters from short-term records showed differences between the groups. Resting heart rate in the exposed group was lower than in the control group but the difference was not statistically significant $(p=0.07)$ and $R-R$ standard deviation was 
significantly higher $(\mathrm{p}=0.01)$ which could probably be a result of the increased parasympathetic activity. The pathomechanism of the influence of fine particulate dust on the cardiovascular system is not fully explained. However, the majority of studies have proven that one of the possible mechanisms is the influence of fine particles on the autonomic nervous system (direct interaction between pulmonary ventilation and autonomic function) or by pulmonary chemoreflex.

Pulmonary chemoreflex initiated from sensory nerves in the bronchial and alveolar regions in the lungs are activated by non-specific effects of sensory nerves. Efferent neural responses include changes in breathing frequency. Neural drive to the heart causes a parasympathetically induced decrease in the heart rate. Also other mechanisms are taken into account: inflammatory response triggered endothelial dysfunction, atherosclerosis and thrombosis, ischaemic response in the myocardium, chemical effects on ion channels function in myocardial cells, translocation of ultrafine particles directly from the lungs into the blood circulation and extrapulmonary organs [21,45-47].

The high percentage of the subjects in each group (45\%) with the mean 24-h heart rate above 87 beats/min is worth noting. Elevated 24-h mean heart rate is an unfavourable symptom. Based on Framingham's research, Kannel proved that the risk of a sudden cardiac death in the people with elevated heart rate was 1.3 times higher than in the people with lower heart rate [13]. Up to the present, over 20 extensive studies have been conducted indicating that the risk of a cardiac death is higher in the people with elevated heart rate (after adjusting for other risk factors, such as age, arterial blood pressure level, diabetes, lipid concentration, BMI, tobacco smoking). Epidemiological research on over 288000 people has shown that the elevated heart rate is associated with the risk of developing arterial hypertension, ischaemic heart disease, and of a sudden cardiac death $[10,11,48]$.
In the present study, the high mean heart rate in the 2 study groups may be a result of performing heavy physical work (energy expenditure over $1500 \mathrm{kcal}$ per 8-h work shift). This interpretation is supported by the fact that the very high HR levels were recorded throughout the day (mean 92.5/min in exposed and 92.9/min in control group) while HR returned to normal during the night (63.1/min and 65.8/min, respectively).

Similar results were reported by Magari et al. in their studies on 39 male boilermakers exposed to particulate air metal (vanadium, nickel, chromium, lead, copper and manganese). They have found a statistically significant increase in SDNN related to a higher concentration of lead and vanadium after adjusting for the mean heart rate, age and smoking habit [16].

In their previous study concerning 40 boilermakers, Magari et al. have found, that the increase in occupational air pollution correlated with the decrease in SDANN [49]. Eninger and Rosenthal in their pilot studies, performed among 5 vehicle maintenance workers, have not found a statistically significant association between occupational fine particles matter PM (2.5) and measures of the heart rate variability [50]. Only the increase in total power spectrum significantly correlated with a higher ambient PM (2.5) concentration.

Considerably more studies have addressed the problem of environmental exposure to particulate air pollution. Their findings indicate that elevated concentrations of particulate dust are associated with a decreased SDNN and SDANN $[8,14,15,51-54]$. It is difficult to compare our results with the studies of other authors, because they were conducted among people environmentally exposed to dusts, where other harmful factors could be also present. Also, the dust content differed in each case, which may have produced a different effect on the neurovegetative regulation. Besides, most of the earlier examined groups were much older than our group, and they consisted of people with a variety of cardiovascular, respiratory and 
other diseases, some of them undergoing medical treatment [55-57].

The analysis of the frequency-domain parameters has shown that power in the range of high frequency (HF) in the exposed group was significantly higher than in the control group. As regards the exposed workers, both the time- and frequency-domain HRV parameters indicated the dominance of the parasympathetic activity in the neurovegetative regulation of the cardiovascular function.

According to Tarkiainen et al. (2003), results of earlier studies suggest that particulate air pollutants can affect the autonomic nervous system in 2 ways: first, through the sympathetic stress response explaining the increased heart rate and reduced HRV, and second, through irritation of the receptors in the lungs and airways leading to augmented vagal control in cardiac autonomic regulation mirrored by the increased r-MSSD [58,59].

Observations of Pope et al. (1999), Tarkiainen et al. (2003) and Timonen et al. (2006) support our results and indicate that air pollution can lead to the increased cardiac vagal control $[8,58,60]$.

The increased parasympathetic activity which has been noted in our study (HF power spectrum) was also observed in animal studies [47].

The prevalence of parasympathetic activity related to the exposure to airborne particulate matter seems to have a physiological justification. Inhaled ambient air particles in low concentrations stimulate receptors in the lungs, thereafter, the impulses are transmitted centrally by vagal nerves and processed in medulla and cerebral cortex. This causes apnea with bradycardia, vasodilatation and systemic hypotension [54].

Markedly, the increased parasympathetic activity may have adverse consequences in some circumstances, for example in the presence of long QT syndrome or poisonings with different substances, it may lead to bradyarrhythmia [50]. Moreover, some data indicate that the airways hyperresponsivness (AHR) could be also connected with activation of the parasympathetic nervous system [56]. Autonomic dysregulation or dysfunction contributes to the pathogenesis of asthma and other airway diseases [61,62]. Some accessible data suggest that asthmatic patients show a tendency for parasympathetic nerve dominance in comparison with healthy controls [63,64].

The studies of Zimmermann and Kalusche (2001) indicate that in the patients with focal ectopy originating from the pulmonary veins, sustained episodes of atrial arrhythmias are mainly dependent on variations of autonomic tone, with a significant shift toward vagal predominance before AF onset [65]. Some accessible data also indicate the connection between autonomic regulation and infections. Hellard et al. (2011) analyzed autonomic regulation in swimmers and found that the weeks which preceded occurrence of not only upper respiratory tract and pulmonary infections but also muscular affections were characterized by an increase in autonomic parasympathetic activity in supine position [66].

In fact, the increase in the parasympathetic nervous system is regarded as beneficial for cardiovascular system. At present, it is difficult to say whether the predominance of the parasympathetic nervous system is definitely beneficial for regulation of the circulatory system, and possibly other physiological functions. Future research is needed to explain the synergy between cardiac autonomic regulation and the autonomic regulation of respiratory, gastrointestinal and muscular systems.

Our results indicate that exposure to fine dust significantly changes neurovegetative regulation of the circulatory function manifested primarily by the increased parasympathetic activity. It may serve as an early indicator of health effects of air pollution. The clinical consequences of those changes may appear after a longer period of exposure. Further research is required in order to determine the dose-response relationship, the dynamics of the neurovegetative disturbances and to assess the long-term effects of exposure to dusts on the cardivascular system. 


\section{AKNOWLEDGEMENTS}

The authors thank Stanisław Maron, Health and Safety Engineer in the plant under study, for his very active and helpful contribution to the organization phase of the field study. We also thank a lot dr Aleksandra Maciejewska from our Institute for performing FT-IR analysis of the dust samples and interpretation of its results.

\section{REFERENCES}

1. Seaton A, MacNee W, Donaldson K, Godden D. Particulate air pollution and acute health effects. Lancet. 1995;345(8943):176-8.

2. Sjogren B. Occupational exposure to dust: inflammation and ischaemic heart disease. Occup Environ Med. 1997;54 (7):466-9.

3. Hammar N, Alfredsson L, Smedberg M, Ahlbom A. Differences in the incidence of myocardial infarction among occupational groups. Scand J Work Environ Health. 1992;18(3): 178-85.

4. Reid PJ, Sluis-Cremer GK. Mortality of white South African gold miners. Occup Environ Med. 1996;53(1):11-6.

5. Tam WW, Wong TW, Wong AH. Effect of dust storm events on daily emergency admissions for cardiovascular diseases. Circ J. 2012;76(3):655-60.

6. Steenland K, Sanderson W. Lung cancer among industrial sand workers exposed to crystalline silica. Am J Epidemiol. 2001;153(7):695-703.

7. Vedal S, Brauer M, White R, Petkau J. Air pollution and daily mortality in a city with low levels of pollution. Environ Health Perspect. 2003;111(1):45-51.

8. Pope CA, Verrier RL, Lovett EG, Larson AC, Raizenne ME, Kanner RE, et al. Heart rate variability associated with particulate air pollution. Am Heart J. 1999;138(5 Pt 1):890-9.

9. Peters A, Perz S, Döring A, Stieber J, Koenig W, Wichmann HE. Increases in heart rate during an air pollution episode. Am J Epidemiol. 1999;150(10):1094-8.
10. Palatini P. Heart rate as a risk factor for atherosclerosis and cardiovascular mortality. Drugs. 1999;57(5):713-24.

11. Palatini P, Casiglia E, Julius S, Pesina AC. High heart rate. A risk factor for cardiovascular death in elderly men. Arch Intern Med. 1999;159(6):585-92.

12. Palatini P. Elevated heart rate as a predictor of increased cardiovascular morbidity. J Hypertens Suppl. 1999;17(3):3-10.

13. Kannel WB, Kannel C, Paffenberger RS Jr, Cupples LA. Heart rate and cardiovascular mortality. The Framingham Study. Am Heart J. 1987;113(6):1489-94.

14. Liao D, Creason J, Shy C, Williams R, Watts R, Zweidinger R. Daily variation of particulate air pollution and poor cardiac autonomic control in the elderly. Environ Health Perspect. 1999;107(7):521-5.

15. Zanobetti A, Gold DR, Stone PH, Suh HH, Schwartz J, Coull BA, et al. Reduction in heart rate variability with traffic and air pollution in patients with coronary artery disease. Environ Health Perspect. 2010;118(3):324-30, http://dx.doi. org/10.1289/ehp.0901003.

16. Magari SR, Schwartz J, Williams PL, Hauser R, Smith TJ, Christiani DC. The association between personal measurements of environmental exposure to particulates and heart rate variability. Epidemiology. 2002;13(3):305-10.

17. Guzzetti S, Piccaluga E, Casati R, Cerutti S, Lombard F, Pagani M, et al. Sympathetic predominance in essential hypertension: A study employing analysis heart rate variability. J Hypertens. 1988;6(9):711-7.

18. Hayano J, Sakakibara S, Yamada M, Ohte N, Fujinami T, Yokoyama K, et. al. Decreased magnitude of heart rate spectral components in coronary artery disease. Circulation. 1990;81(4):1217-24.

19. Baranowski R. [Predictive value analysis of sinus rhythm]. Kardiol Pol. 1991;3(3):190-4. Polish.

20. Woźniak H, Stroszejn-Mrowca G, Kita N. [Dust exposure in a pottery plant assessed by using GRIMM dust monitor]. Med Pr. 2002;53(5):405-11. Polish.

21. Nemmar A, Hoylaerts MF, Hoet PH, Nemery M. Possible mechanism of the cardiovascular effects of inhaled particles: 
systemic translocation and prothrombotic effects. Toxicol Lett. 2004;149(1-3):243-53.

22. PN-Z-04008-7:2002P. [Air purity protection - Sampling methods - Principles of air sampling in work place and interpretation of results]. Warszawa: Polski Komitet Normlizacji, Miar i Jakości; 2002. Polish.

23. PN-Z-04030-05:1991P. [Air purity protection. Tests for dust. Determination of total dust in work places by filtration-gravimetric method]. Warszawa: Polski Komitet Normalizacji, Miar i Jakości; 1991. Polish.

24. PN-Z-04030-06:1991P. [Air purity protection. Tests for dust. Determination of respirable dust in work places by filtrationgravimetric method]. Warszawa: Polski Komitet Normalizacji, Miar i Jakości; 1991. Polish.

25. PN-EN 481:1998P. [Workplace atmospheres - Size fraction definitions for measurement of airborne particles]. Warszawa: Polski Komitet Normalizacji, Miar i Jakości; 1998. Polish.

26. PN-EN 1540:2004P. [Workplace atmospheres - Terminology]. Warszawa: Polski Komitet Normalizacji, Miar i Jakości; 2004. Polish.

27. Piotrowicz R. [Standards for selected procedures in nonivasive electrocardiology]. Elektrofizjol Stymul Serca. 1998;5(Suppl II):1-49. Polish.

28. Malik M. Heart rate variability, standards of measurement, physiological interpretation, and clinical use. Circulation. 1996;93(1):1043-65.

29. Staessen J, Fagard R, Lijnen P, Thijs L, Van Hoof R, Amery A. Reference values for ambulatory blood pressure: A metaanalysis. J Hypertension. 1990;8(Suppl 6):57-64.

30. Ugajin T, Hozawa A, Ohkubo T, Asayama K, Kikuya M, Obara $\mathrm{T}$, et al. White-coat hypertension as a risk factor for the development of home hypertension: The Ohasama study. Arch Intern Med. 2005;165(13):1541-6.

31. Verdecchia P, Angeli F, Gattobigio R, Borgioni C, Castellani C, Sardone M, et al. The clinical significance of white-coat and masked hypertension. Blood Press Monit. 2007;12(6):387-9, http://dx.doi.org/10.1097/MBP. 0b013e32824958e5.
32. Hansen TW, Jeppesen J, Rasmussen S, Ibsen H, Torp-Pedersen C. Ambulatory blood-pressure monitoring and risk of cardiovascular disease. A population based study. Am J Hypertens. 2006;19(3):243-50, http://dx.doi.org/10.1016/ j.amjhyper.2005.09.018.

33. Boggia J, Li Y, Thijs L, Hansen TW, Kikuya M, BjorklundBodegard K, et al. International Database on Ambulatory blood pressure monitoring in relation to Cardiovascular Outcomes (IDACO) investigators. Prognostic accuracy of day versus night ambulatory blood pressure: A cohort study. Lancet. 2007;370(9594):1219-29, http://dx.doi.org/10.1016/ S0140-6736(07)61538-4.

34. Tatasciore A, Renda G, Zimarino M, Soccio M, Bilo G, Parati G, et al. Awake systolic blood pressure variability correlates with target organ damage in hypertensive subjects. Hypertension. 2007;50(2):325-32, http://dx.doi.org/10.1161/ HYPERTENSIONAHA.107.090084.

35. Yavuz BB, Yavuz B, Tayfur O, Cankurtaran M, Halil M, Ulger Z, et al. White coat effect and its clinical implications in the elderly. Clin Exp Hypertens. 2009;31(4):306-15, http://dx.doi.org/10.1080/10641960802621341.

36. Grassi G, Bombelli M, Seravalle G, Brambilla G, Dell'oro R, Mancia G. Role of ambulatory blood pressure monitoring in resistant hypertension. Curr Hypertens Rep. 2013;15(3): 232-7, http://dx.doi.org/10.1007/s11906-013-0349-0.

37. Winer BJ, Brown DR, Michels KM. Statistical principles in experimental design. Boston: McGraw-Hill Inc; 1991.

38. Fisher LD, van Belle G. Biostatistics. A methodology for the health sciences. New York: John Wiley\& Sons, Inc; 1993.

39. Hosmer DW, Lemeshow S. Applied logistic regression. New York: John Wiley \& Sons, Inc; 1989.

40. Hypertension control. Report of a WHO Expert Committee. World Health Organ Tech Rep Ser. 1996;862:1-83.

41. Cuspidi C, Rescaldani M, Sala C, Negri F, Grassi G, Mancia G. Prevalence of electrocardiographic left ventricular hypertrophy in human hypertension: An updated review. J Hypertens. 2012;30(11):2066-73, http://dx.doi.org/10.1097/ HJH.0b013e32835726a3. 
42. Gadzicka E, Bortkiewicz A, Zmyślony M. [Assesment of selected physiological parameters in different occupational groups exposed to high frequency electromagnetic fields. III. A 24-h monitoring of arterial blood pressure]. Med Pr. 1997;48(1):17-24. Polish.

43. Bortkiewicz A, Zmyślony M, Gadzicka E, Pałczyński C. Ambulatory ECG monitoring in workers exposed to MF electromagnetic fields. J Med Eng Technol. 1997;21(2):41-6.

44. Bortkiewicz A, Zmyślony M, Gadzicka E. [Exposure to electromagnetic fields with frequencies of $50 \mathrm{~Hz}$ and changes in circulatory system in workers of electrical power stations]. Med Pr. 1998;49(3):261-75. Polish.

45. Huang SL, Hsu MK, Chan CC. Effects of submicrometer particle composition on cytokine production and lipid peroxidation of human bronchial epithelial cells. Environ Health Perspect. 2003;111(4):478-82, http://dx.doi.org/10.1289/ ehp.5519.

46. Utell MJ, Frampton MW, Zareba W, Devlin RB, Cascio WE. Cardiovascular effects associated with air pollution: potential mechanisms and methods of testing. Inhal Toxicol. 2002;14(12): 1231-47, http://dx.doi.org/10.1080/08958370290084881.

47. Godleski JJ, Verrier RL, Koutrakis P, Catalano P. Mechanisms of morbidity and mortality from exposure to ambient air particles. Research Report 91. Cambridge, MA: Health Effects Institute; 2000.

48. Purcell $\mathrm{H}$. Is heart rate a prognostic factor for cardiovascular disease? Dialog Cardiovasc Med. 2001;6(1):32-6.

49. Magari SR, Hauser R, Schwartz J, Williams PL, Smith TJ, Christiani DC. Association of heart rate variability with occupational and environmental exposure to particulate air pollution. Circulation. 2001;104(9):986-91, http://dx.doi. org/10.1161/hc3401.095038.

50. Eninger RM, Rosenthal FS. Heart rate variability and particulate exposure in vehicle maintenance workers: A pilot study. J Occup Environ Hyg. 2004;1(8):493-9, http://dx.doi. org/10.1080/15459620490468223.

51. Pope CA 3rd, Hansen ML, Long RW, Nielsen KR, Eatough NL, Wilson WE, et al. Ambient particulate air pollution, heart rate variability, and blood markers of inflammation in a panel of elderly subjects. Environ Health Perspect. 2004;112(3):339-45, http://dx.doi.org/10.1289/ ehp.6588.

52. Devlin RB, Ghio AJ, Kehrl H, Sanders G, Cascio W. Elderly humans exposed to concentrated air pollution particles have decreased heart rate variability. Eur Respir J (Suppl). 2003;40:76-80, http://dx.doi.org/10.1183/0903193 6.03.00402403.

53. Holguin F, Tellez-Rojo MM, Hernandez M, Cortez M, Chow JC, Watson JG, et al. Air pollution and heart rate variability among the elderly in Mexico City. Epidemiology. 2003;14(5):521-7, http://dx.doi.org/10.1097/01.ede. 0000081999.15060.ae.

54. Chan CC, Chuang KJ, Shiao M, Lin LY. Personal exposure to submicrometer particles and heart rate variability in human subjects. Environ Health Perspect. 2004;112(10):1063-7, http://dx.doi.org/10.1289/ehp.6897.

55. Hampel R, Schneider A, Brüske I, Zareba W, Cyearys J, Rückerl R, et al. Altered cardiac repolarization in association with air pollution and air temperature among myocardial infarction survivors. Environ Health Perspect. 2010;118(12):1755-61, http://dx.doi.org/10.1289/ ehp.1001995.

56. Schneider A, Hampel R, Ibald-Mulli A, Zareba W, Schmidt G, Schneider R, et al. Changes in deceleration capacity of heart rate and heart rate variability induced by ambient air pollution in individuals with coronary artery disease. Part Fibre Toxicol. 2010;7:29, http://dx.doi.org/10.1186/1743-8977-7-29.

57. Rich DQ, Zareba W, Beckett W, Hopke PK, Oakes D, Frampton MW, et al. Are ambient ultrafine, accumulation mode, and fine particles associated with adverse cardiac responses in patients undergoing cardiac rehabilitation? Environ Health Perspect. 2012;120(8):1162-9, http://dx.doi. org/10.1289/ehp.1104262. Erratum in: Environ Health Perspect. 2012;120(9):A345.

58. Tarkiainen TH, Timonen KL, Vanninen EJ, Alm S, Hartikainen JEK, Pekkanen J. Effect of acute carbon monoxide 
exposure on heart rate variability in patients with coronary artery disease. Clin Physiol Funct Imaging. 2003;23(2): 98-102.

59. Stone PH, Godleski JJ. First steps toward understanding the pathophysiologic link between air pollution and cardiac mortality. Am Heart J. 1999;138(5 Pt 1):804-7.

60. Timonen KL, Vanninen E, de Hartog J, Ibald-Mulli A, Brunekreef B, Gold DR, et al. Effects of ultrafine and fine particulate and gaseous air pollution on cardiac autonomic control in subjects with coronary artery disease: The ULTRA study. J Exp Sci Environ Epidemiol. 2006;16(4):332-41, http://dx.doi.org/10.1038/sj.jea.7500460.

61. Pichon A, de Bisschop C, Diaz V, Denjean A. Parasympathetic airway response and heart rate variability before and at the end of methacholine challenge. Chest. 2005;127(1):23-9, http://dx.doi.org/10.1378/chest.127.1.23.

62. Lutz W, Sulkowski WJ. Vagus nerve participates in regulation of the airways: inflammatory response and hyperreactivity induced by occupational asthmogens. Int J Occup Med Environ Health. 2004;17(4):417-31.

63. Sato K, Kawamura T, Abo T. "Senobi" stretch ameliorates asthma symptoms by restoring autonomic nervous system balance. J Investig Med. 2010;58(8):968-70, http://dx.doi. org/10.231/JIM.0b013e3181f9167b.

64. Lutfi MF. Autonomic modulations in patients with bronchial asthma based on short-term heart rate variability. Lung India. 2012;29(3):254-8, http://dx.doi.org/10.4103/09702113.99111.

65. Zimmermann M, Kalusche D. Fluctuation in autonomic tone is a major determinant of sustained atrial arrhythmias in patients with focal ectopy originating from the pulmonary veins. J Cardiovasc Electrophysiol. 2001;12(3):285-91.

66. Hellard P, Guimaraes F, Avalos M, Houel N, Hausswirth C, Toussaint JF. Modeling the association between HR variability and illness in elite swimmers. Med Sci Sports Exerc. 2011;43(6): 1063-70, http://dx.doi.org/10.1249/MSS.0b013e318204de1c.

This work is available in Open Access model and licensed under a Creative Commons Attribution-NonCommercial 3.0 Poland License - http://creativecommons.org/ licenses/by-nc/3.0/pl/deed.en. 